\title{
Consequences of bottle-feeding to the oral facial development of initially breastfed children
}

\author{
Conseqüências do uso da mamadeira para o desenvolvimento orofacial \\ em crianças inicialmente amamentadas ao peito
}

\section{Karina Camillo Carrascoza1, Rosana de Fátima Possobon², Laura Mendes Tomita ${ }^{3}$, Antônio Bento Alves de Moraes ${ }^{4}$}

\section{Resumo}

Objetivo: Identificar e avaliar as possíveis conseqüências do uso da mamadeira sobre o desenvolvimento orofacial em crianças que foram amamentadas até, pelo menos, os 6 meses de vida.

Método: Participaram do estudo 202 crianças ( 4 anos de idade) que freqüentaram o Programa de Atenção Precoce à Saúde. A amostra foi dividida em: G1 (crianças que utilizaram apenas copo para ingestão de líquidos) e G2 (utilizaram mamadeira).

Resultados: Selamento labial foi observado em $82 \%$ das crianças do $\mathrm{G} 1$ e em $65 \%$ do G2 ( $p=0,0065)$. Repouso da língua no arco superior foi encontrado em $73 \%$ das crianças do G1 e em $47 \%$ do $G 2$ ( $p<0,0001)$. Observou-se maior ocorrência de respiração nasal em $69 \%$ do G1 e em $37 \%$ do $G 2(p<0,0001)$. A maxila mostrou-se normal em $90 \%$ do $G 1$ e em $78 \%$ do $G 2(p=0,0206)$.

Conclusão: Usar mamadeira, mesmo entre crianças que receberam aleitamento materno, interfere negativamente sobre o desenvolvimento orofacial.

J Pediatr (Rio J). 2006;82(5):395-7: Alimentação artificial, aleitamento materno.

\section{Introdução}

A amamentação é apontada como um fator determinante para o desenvolvimento craniofacial adequado, por promover intenso exercício da musculatura orofacial, estimulando favoravelmente as funções da respiração, deglutição, mastigação e fonação ${ }^{1}$.

1. Doutoranda em Saúde da Criança e do Adolescente, Faculdade de Ciências Médicas, Universidade Estadual de Campinas (UNICAMP), Campinas, SP

2. Professora Doutora, Faculdade de Odontologia de Piracicaba, UNICAMP, Piracicaba, SP.

3. Doutoranda em Odontologia, Faculdade de Odontologia de Piracicaba, UNICAMP, Piracicaba, SP.

4. Doutor. Professor titular, Faculdade de Odontologia de Piracicaba, UNICAMP, Piracicaba, SP.

Artigo submetido em 07.02.06, aceito em 25.05.06.

Como citar este artigo: Carrascoza KC, Possobon RF, Tomita LM, de Moraes AB. Consequences of bottle-feeding to the oral facial development of initially breastfed children. J Pediatr (Rio J). 2006;82:395-7.

\section{Abstract}

Objective: To identify and assess the possible consequences of bottle-feeding on the oral facial development of children who were breastfed up to at least six months of age.

Method: Two hundred and two children (4 years of age) enrolled in an early health attention program participated in the study. The sample was divided into two groups: G1 (children who used only a cup to drink) and G2 (those who used a bottle).

Results: Lip closure was observed in $82 \%$ of the children in G1 and in $65 \%$ of those in $\mathrm{G} 2(\mathrm{p}=0.0065)$. The tongue coming to rest in the maxillary arch was found in $73 \%$ of the children in G1 and in $47 \%$ of those in G2 ( $p=0.0001)$. Nasal breathing was observed in $69 \%$ of G1 and in $37 \%$ of G2 $(p=0.0001)$. The maxilla was shown to be normal in $90 \%$ of $G 1$ and in $78 \%$ of $G 2$ ( $p=0.0206)$.

Conclusion: Use of the bottle, even among breastfed children interferes negatively with oral facial development.

J Pediatr (Rio J). 2006;82(5):395-7: Bottle feeding, breastfeeding.

Os movimentos de ordenha favorecem o adequado selamento labial durante o estado de repouso ${ }^{2}$ e a correção do retrognatismo mandibular fisiológico. Além disso, beneficiam o correto posicionamento da língua na região palatina dos incisivos centrais, devido à aquisição de tonicidade, resultado da intensa atividade dos músculos da língua ${ }^{3}$.

Apesar das medidas de incentivo ao aleitamento adotadas pelos hospitais contemplados com o título de Amigo da Criança ${ }^{4}$ e da contra-indicação ao uso de mamadeira pela Norma Brasileira para Comercialização de Alimentos para Lactentes ${ }^{5}$, os achados científicos mostram que existem dois momentos críticos para a apresentação desse tipo de utensílio à criança: logo após o parto e por volta do quarto mês de vida 6 .

A primeira situação ocorre em função de problemas relacionados à prática da amamentação, que dificultam o ganho de peso pela criança. Neste caso, é comum a prescrição, por parte dos profissionais de saúde, de fórmulas infantis, geralmente oferecidas na mamadeira, para 
complementar/substituir o leite materno, quando o correto seria investigar as dificuldades apresentadas pela nutriz e oferecer orientação sobre o manejo da amamentação7.

A introdução da mamadeira à rotina alimentar da criança, por volta do quarto mês de vida, está provavelmente relacionada ao término da licença-maternidade e ao retorno da mãe ao trabalho. Este é um momento caracterizado por muitos conflitos, tais como a escolha de um cuidador para o bebê e a forma de alimentação utilizada nos momentos de ausência da mãe ${ }^{8}$. A mãe que opta por deixar a criança aos cuidados de instituições (creches/escolas), onde geralmente é estabelecido o uso de mamadeira, não pode exigir a utilização de copos para a alimentação do seu filho. Os profissionais dessas instituições justificam essa prática pelo pequeno número de funcionários em relação ao número de crianças e pela dificuldade encontrada em alimentá-las usando copo ${ }^{9}$.

A literatura é consistente em afirmar que usar mamadeira, em detrimento do aleitamento, acarreta conseqüências à saúde da criança ${ }^{10}$. Porém, nenhum trabalho relata os efeitos da utilização da mamadeira sobre o desenvolvimento orofacial de crianças que foram amamentadas ao peito até o sexto mês de vida e que também utilizaram mamadeira.

Assim sendo, o objetivo deste estudo foi identificar e avaliar as possíveis conseqüências do uso da mamadeira sobre o desenvolvimento orofacial em crianças que foram amamentadas (exclusivamente ou não) até, pelo menos, os 6 meses de vida.

\section{Métodos}

Os participantes foram 202 crianças (idade: 4 anos) que freqüentaram o Centro de Pesquisa e Atendimento Odontológico para Pacientes Especiais (Cepae, Faculdade de Odontologia de Piracicaba, Universidade Estadual de Campinas UNICAMP) em 2004. O Cepae acompanha as crianças do período gestacional ao quinto ano de vida. A gestante participa de palestras educativas e, após o nascimento, a díade mãe-bebê participa do Grupo de Incentivo ao Aleitamento Materno Exclusivo, do qual recebe apoio para manter a amamentação e evitar a introdução de mamadeira/ chupeta. Aos 3, 4 e 5 anos de idade, as crianças passam pela avaliação ortodôntica e fonoaudiológica, uma das atividades oferecidas pelo Cepae.

O Grupo 1 foi composto pelo total de crianças participantes do Cepae que utilizaram apenas copo para ingestão de alimentos líquidos até 4 anos de idade (nunca usaram mamadeira) $(n=101)$. Para que o Grupo 2 fosse composto pelo mesmo número de crianças do G1, a amostra foi selecionada aleatoriamente, dentro do universo de pacientes do Cepae que utilizaram mamadeira durante, no mínimo, 1 ano. Desta forma, não foi necessário calcular o tamanho da amostra.

Foram incluídas na amostra crianças amamentadas por, no mínimo, 6 meses, e excluídas aquelas que apresentaram outros hábitos de sucção além da mamadeira (chupeta/ dedo). Esse cuidado com a seleção da amostra pretendeu evitar a interferência dessas variáveis sobre as conseqüências específicas do uso da mamadeira sobre o desenvolvimento orofacial.

$\mathrm{Na}$ avaliação ortodôntica e fonoaudiológica, todas as crianças foram examinadas por uma dentista e uma fonoaudióloga, as quais foram treinadas pelos pesquisadores, a fim de padronizar o exame, sem, entretanto, conhecer os objetivos da pesquisa. Os seguintes dados foram anotados na ficha de levantamento de informações: (1) oclusão: mordida aberta anterior (ausência de toque entre incisivos superiores e inferiores durante oclusão dos posteriores); mordida cruzada posterior (contato entre cúspides vestibulares dos dentes posteriores superiores e sulcos oclusais dos posteriores inferiores); (2) aspectos musculares: postura de lábio (presença/ausência de toque entre lábio superior e inferior durante estado de repouso); local de repouso da língua (entre arcos, no arco superior ou no arco inferior); (3) aspecto articulatório: fonoarticulação dos fonemas linguodentais /t/, /d/, /n/, /l/ e linguoalveolares /s/ e /z/ (não foram consideradas trocas fonológicas, e sim fonéticas, que ocorrem devido à alteração do processo articulatório.); (4) padrão respiratório: oral, nasal e misto (predominantemente nasal ou predominantemente oral); (5) profundidade do palato: normal ou ogival; (6) formato do arco superior: atrésico ou semicircular; (7) face: simetria ou assimetria.

As análises estatísticas foram realizadas pelos testes qui-quadrado e exato de Fisher (nível de significância = $5 \%)$.

O projeto foi aprovado pelo comitê de ética em pesquisa da Faculdade de Odontologia de Piracicaba, UNICAMP (Protocolo no 084/2004).

\section{Resultados}

Observou-se selamento labial em $65 \%$ das crianças que usaram mamadeira e em $82 \%$ das crianças que utilizaram copo $(p=0,0065)$.

Em relação ao local de repouso da língua, entre as crianças que utilizaram copo, $73 \%$ apresentaram repouso de língua no arco superior (posição desejada). Dentre as crianças que utilizaram mamadeira, 53\% apresentavam repouso de língua no arco inferior ou entre os arcos (alteração de normalidade), revelando hipotonicidade dos músculos linguais ( $p<0,0001)$.

Houve maior ocorrência de normalidade respiratória (nasal) entre as crianças que utilizaram copo (69\%). Entre aquelas que usaram mamadeira, $63 \%$ apresentavam respiração oral ou mista ( $p<0,0001)$.

O formato do arco superior apresentou-se diferente entre as crianças dos dois grupos, sendo que atresia maxilar esteve presente em $22 \%$ das crianças que usaram mamadeira e em $10 \%$ das crianças que usaram o copo $(p=0,0206)$.

As variáveis ocorrência de maloclusões, fonoarticulação, profundidade do palato e presença de assimetria facial não apresentaram diferença estatística $(p>0,05)$. 


\section{Discussão}

Houve diferença estatística entre os grupos quanto ao selamento labial, sendo predominante entre as crianças que usaram copo, demonstrando a influência positiva do exercício realizado durante a ordenha do leite materno ${ }^{2}$.

Além do selamento labial, os movimentos de ordenha favorecem o posicionamento da língua na região palatina dos incisivos centrais, devido à aquisição de tonicidade, resultado da intensa atividade dos músculos da língua ${ }^{3}$, o que impede a passagem de ar pela boca, favorecendo a instalação e manutenção da respiração nasal. Esse tipo de respiração, além de aquecer, umidificar e filtrar o ar antes que ele chegue aos pulmões, é considerado matriz funcional para o crescimento da maxila. A passagem de ar pelo nariz exerce pressão sobre o palato, fazendo com que ele abaixe e sofra expansão. Esse fenômeno possibilita que os ossos da face acompanhem o crescimento corporal, gerando espaço para a adequada erupção dos dentes ${ }^{11}$.

Ao usar mamadeira, a língua atua apenas como dosador da saída de leite, tornando-se hipotônica e incapaz de permanecer na posição correta ${ }^{10}$, o que confirma os resultados do presente estudo relativos à maior ocorrência de hipotonicidade e conseqüente repouso de língua em local incorreto entre as crianças que utilizaram mamadeira.

A falta de função da língua, que faz com que ela repouse sobre o arco inferior, permite que o ar entre pela boca, comprometendo a respiração nasal ${ }^{12}$. Novamente, os resultados deste estudo corroboram os achados da literatura, quando mostram que mais de $60 \%$ das crianças que usaram mamadeira apresentavam respiração oral ou mista.

A ausência da passagem de ar pelo nariz pode provocar atresia do arco superior ${ }^{13}$. Essa relação também foi comprovada pelo presente estudo, que revelou maior ocorrência de atresia maxilar em crianças que usaram mamadeira.

$O$ repouso da língua no arco inferior também pode agir como matriz funcional para o crescimento inadequado da mandíbula. Essa ocorrência, associada à ausência da passagem de ar pelo nariz, pode levar ao desenvolvimento de mordida cruzada posterior. Köhler ${ }^{14}$ ainda acrescenta mais um agravante, pois relata que o bucinador, músculo responsável pela obtenção do leite da mamadeira, torna-se hipertrófico em casos de sucção prolongada, agravando a desproporção de crescimento maxila/mandíbula. Essa tonicidade inadequada, além de causar mordida cruzada e apinhamento dental, pode levar a alterações seqüenciais na face, como o estreitamento excessivo da maxila, atresia do palato, desvio de septo e comprometimento da estética e função do nariz.

Os resultados do presente estudo não mostraram diferença estatística, em relação à oclusão, entre os grupos. Entretanto, vale ressaltar que as crianças foram examinadas aos 36 meses de idade e que, por serem bastante jovens, poderiam ainda não apresentar mordida cruzada posterior. Essa hipótese é reforçada pela maior ocorrência de dois fatores desencadeantes da mordida cruzada posterior entre as crianças que usaram mamadeira: atresia da maxila e posicionamento de língua no arco inferior. Pelo fato de os resultados deste estudo não evidenciarem relação direta entre mordida cruzada posterior e uso de mamadeira, sugere-se o estudo de sujeitos com idade superior.

Assim, os resultados deste estudo mostraram que o uso da mamadeira, mesmo entre crianças que receberam aleitamento materno, interfere negativamente sobre o desenvolvimento orofacial.

\section{Referências}

1. Baldrigui SEZM, Pinzan A, Zwicker CV, Michelini CRS, Barros DR, Elias F. A importância do aleitamento natural na prevenção de alterações miofaciais e ortodônticas. Rev Dent Press Ortod Ortop Facial. 2001;6:111-21.

2. Serra-Negra JMC, Pordeus IA, Rocha Jr JF. Estudo da associação entre aleitamento, hábitos bucais e maloclusões. Rev Odontol Univ Sao Paulo. 1997;11:79-86.

3. Neiva FC, Cattoni DM, Ramos JL, Issler H. Desmame precoce: implicações para o desenvolvimento motor-oral. J Pediatr (Rio J). 2003;79:7-12.

4. Vannuchi MTO, Monteiro CA, Rea MF, Andrade SM, Matsuo T. Iniciativa Hospital Amigo da Criança e aleitamento materno em unidade de neonatologia. Rev Saude Publica. 2004;38:422-8.

5. Norma brasileira para comercialização de alimentos para lactentes. International baby food action network. Resoluções da Diretoria Colegiada /ANVISA. 2002. http://www.ibfan.org.br/ rdc222.htm. Acesso: 23/06/2006.

6. Oliveira RL, Silva AN. Aspectos legais do aleitamento materno: cumprimento da lei por hospitais de médio e de grande porte de Maceió. Rev Bras Saude Matern Infant. 2003;3:43-8.

7. Rea MF. Reflexões sobre a amamentação no Brasil: de como passamos a 10 meses de duração. Cad Saude Publica. 2003;19:S37-S45.

8. Lamounier JA. O efeito de bicos e chupetas no aleitamento materno. J Pediatr (Rio J). 2003;79:284-6.

9. Dowling DA, Meier PP, DiFiori JM, Blatz MA, Martin RJ. Cupfeeding for preterm infants: mechanics and safety. J Hum Lact. 2002;18:13-20.

10. Jorge MD. Hábitos bucais - Interação entre odontopediatria e fonoaudiologia. J Bras Odontop Odont Bebe. 2002;5:342-50.

11. Legovic M, Ostric L. The effects of feeding methods on the growth of the jaws in infants. ASDC J Dent Child. 1991;58:253-5.

12. Ferreira MIDT, Toledo OA. Relação entre tempo de aleitamento materno e hábitos bucais. Rev ABO Nac. 1997;5:317-20.

13. Fagundes ALA, Leite ICG. Amamentação e maloclusão: revisão de literatura. J Bras de Fonoaudiologia. 2001;2:229-32.

14. Köhler NRW. Distúrbios miofuncionais: considerações sobre seus fatores etiológicos e conseqüências sobre o processo de crescimento/desenvolvimento da face. Rev Dent Press Ortod Ortop Facial. 2000;5:66-79.

Correspondência:

Karina Camillo Carrascoza

Avenida Limeira, 901, Bairro Areião

CEP 13414-903 - Piracicaba, SP

Tel.: (19) 3412.5363

Fax: (19) 3412.5218

E-mail: carrascoza@fop.unicamp.br 